\title{
An ascending non-obstructive model for chronic pyelonephritis in BALB/c mice
}

\author{
R. GUPTA*, N. K. GANGULY†, VARINDER AHUJA*, KUSEM JOSHI† and SAROJ SHARMA* ${ }^{*}$ \\ * Department of Microbiology, Government Medical College, Sector: 38-B, Chandigarh $160-014$ and $\dagger$ Department \\ of Experimental Medicine and Department of Pathology, PGI, Chandigarh 160-012, India
}

\begin{abstract}
Summary. Chronic pyelonephritis was successfully produced in female BALB/c mice with Escherichia coli after introduction of the bacterial inoculum by the ascending route. E. coli strain 31-B, a nalidixic acid-resistant derivative of strain TN675 expressing type-1 pili, and E. coli strain BH-5, a mutant of 31-B, not expressing type-1 pili, were used in the model. Both the strains were able to induce chronic renal inflammation in the experimental animals. Whereas the initial colonisation was greater with strain 31-B, its non-pilate mutant BH-5 caused a significantly greater inflammatory response and also caused renal scarring observable 5 months after the infection.
\end{abstract}

\section{Introduction}

The most common form of extra-intestinal infection caused by Escherichia coli is urinary tract infection, $c$. $80 \%$ of which is caused by this micro-organism. ${ }^{1}$ Human infections occur most commonly in patients with anatomically and functionally normal urinary tracts and involve spontaneous ascent of bacteria from the urethra to the kidney through the bladder, or occasionally infection arises via the blood stream. ${ }^{2-4}$ Epidemiological studies can identify an association between certain bacterial properties and virulence but understanding the pathogenesis of the disease requires the use of animal models. These animal models preferably should not involve manipulation of the urinary tract. ${ }^{5}$

The animal species used must share with man those aspects of the urinary tract that are important in the pathogenesis of the disease. Experimental pyelonephritis is relatively easy to establish in rats because of spontaneous vesico-ureteral reflux (VUR). ${ }^{5}$ However, rat uro-epithelial cells do not match human cells in the expression of receptors for p-fimbriae. ${ }^{6,7}$ Furthermore, the globoside isolated from the rat kidney contains a Gal $\alpha(1-3)$ Gal $\beta$ linkage instead of the critical Gal $\alpha(1-4) \mathrm{Gal} \beta$ linkage present in human globoside. ${ }^{8}$ Thus the rat is of questionable value for use in evaluating the pathogenesis of pyelonephritis. The rat model available for chronic pyelonephritis employs direct inoculation of organisms in the kidney. ${ }^{9}$

Received 26 Aug. 1994; revised version accepted 29 Dec. 1994. $\ddagger$ Correspondence should be sent to Dr S. Sharma.
In contrast to rat tissue, mouse renal tissue contains an appreciable concentration of Gal $\alpha(1-4) \mathrm{Gal} \beta$ containing glycolipid. ${ }^{10} \mathrm{An}$ ascending model for acute pyelonephritis is available both in the rat and the mouse. ${ }^{11-14}$ A model employing the ascending route of infection for developing chronic pyelonephritis has not yet been standardised in either animal species. In the present study, a model for chronic pyelonephritis in BALB/c mice was devised in which an ascending route of infection was employed.

\section{Materials and methods}

\section{Bacterial strains}

Two strains of Escherichia coli were used for the study. (i) Strain 31-B, a nalidixic acid-resistant derivative of strain $\mathrm{TN}$ 675. This strain produces mannose-sensitive type-1 pili and is uropathogenic. (ii) Strain BH-5, a mutant defective in the ability to produce type- 1 pili. Both these strains were kindly supplied by Takeda Chemical Industries Ltd, Japan.

\section{Bacterial cultivation}

$E$ coli strains were maintained on nutrient agar slants. The strains were grown in static culture in Brain Heart Infusion Broth (BHI; Hi-media, Bombay, India) at $37^{\circ} \mathrm{C}$ for $18 \mathrm{~h}$. The bacteria were harvested by centrifugation at $500 \mathrm{~g}$ for $30 \mathrm{~min}$, washed three times and suspended in phosphate-buffered saline (PBS, $\mathrm{pH} \mathrm{7.3)} \mathrm{to} \mathrm{the} \mathrm{desired} \mathrm{concentration} \mathrm{of}$ $2 \times 10^{9} \mathrm{cfu} / \mathrm{ml}$. 


\section{Animals}

Female BALB/c mice (Central Animal House, Punjab University, Chandigarh. India) weighing 20-30 g were used for the study. They were fed on standard antibiotic-free synthetic feed (JDB Agencies Private Ltd, India) Mice without bacteriuria, as confirmed by culture. were selected for the study.

\section{Induction of chronic pyelonephritis}

The original method for inducing acute pyelonephritis of Hagberg et al..$^{6}$ and Schaeffer et al. ${ }^{15}$ was used with the slight modifications outlined by Sinha et $a l{ }^{13}$ for the introduction of bacterial inoculum by the ascending route. A soft intermediate non-radioopaque polyethylene tubing with an outer diameter of $0.61 \mathrm{~mm}$ (Clay Adams, USA) was inserted into the urethral meatus and advanced into the bladder. The inoculum $(0 \cdot 1 \mathrm{ml})$ was injected slowly into the bladder to avoid leakage and the catheter was withdrawn carefully. To achieve persistent infection, these animals were re-infected 15 days after the first infection by the same method. To achieve renal scarring, animals were again infected 16 weeks later.

Groups of six mice, infected with either strain of $E$. coli, were killed by cervical dislocation 4 weeks, 8 weeks, 12 weeks, 16 weeks and 20 weeks later. The viscera of the mice were exposed after thoroughly cleaning the abdomen with alcohol. The kidneys were removed aseptically and were examined bacteriologically and histopathologically. Blood cultures were done to exclude bacteraemia.

\section{Bacteriological examination}

One-half of each kidney was placed in a sterile tube and weighed. The kidney tissue was homogenised in a Corning glass homogeniser with $1.0 \mathrm{ml}$ of sterile PBS. Serial dilutions of the homogenised mass in PBS were plated on MacConkey agar plates. The plates were incubated at $37^{\circ} \mathrm{C}$ for $24 \mathrm{~h}$ and the viable counts were determined.

\section{Histopathological examination}

The kidney tissue, preserved in formalin, was dehydrated in an ethanol gradient of $70-100 \%$. The tissue was embedded in paraffin, sectioned and stained with haematoxylin and eosin.

\section{Histopathological grading}

Grading of the severity of pathological lesion was done according to the method of Garg et al. ${ }^{16}$

\section{Results}

Chronic pyelonephritis was induced in BALB/c mice with both $E$. coli strains $31-\mathrm{B}$ and $\mathrm{BH}-5$. The bacteriological studies (table, fig. 1) revealed that the pilate $E$. coli strain 31-B was able to colonise BALB/c mouse renal tissue much better than its non-pilate mutant, BH-5, $(\mathrm{p}<0.05)$ when assessed 4 weeks after infection.

Eight weeks after infection a significant decrease in the colonisation by both strains was observed ( $\mathrm{p}<$ 0.05 ) when compared with colonisation at 4 weeks, but the pilate strain still showed higher bacterial counts than the non-pilate mutant. However, this difference was not significant $(p>0 \cdot 01)$. However, at 12 weeks the non-pilate mutant showed a significant rise in

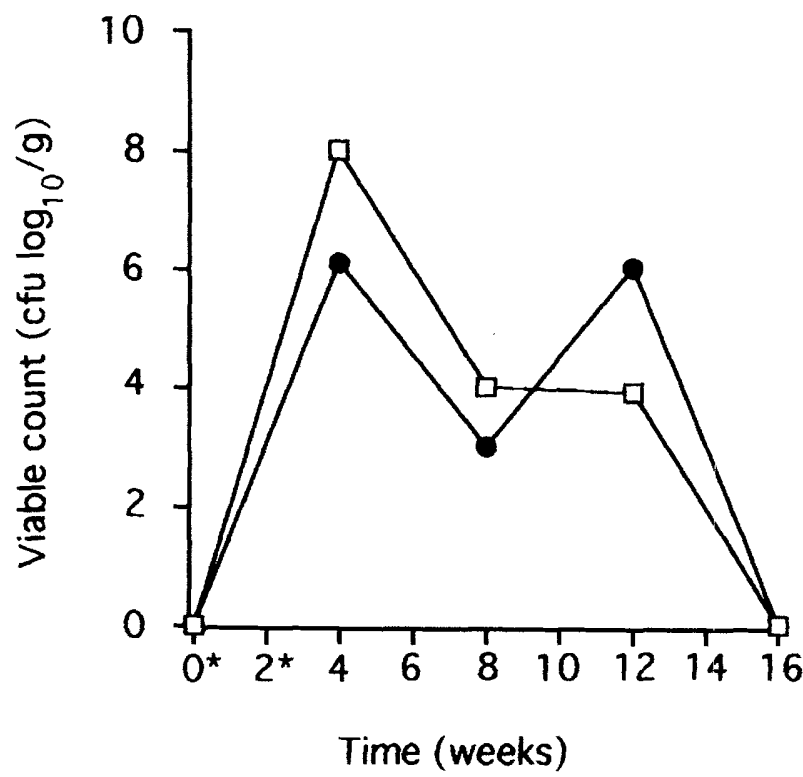

Fig. 1. Renal bacterial load at time intervals after infection, *, time of intra-urethral inoculation; - $\square-$, E. coli $31-\mathrm{B} ;--\mathbf{-}$, E. coli $\mathrm{BH}-5$.

Table. Comparison of mouse kidney bacterial load of $E$. coli $31-\mathrm{B}$ and of $E$. coli $\mathbf{B H}-5$ at different time intervals after the first infection

\begin{tabular}{|c|c|c|c|c|c|}
\hline \multirow{2}{*}{ Group of mice } & \multicolumn{5}{|c|}{ Viable count of bacteria in kidney after } \\
\hline & 4 weeks & 8 weeks & 12 weeks & 16 weeks & 20 weeks \\
\hline $\begin{array}{l}\text { Group I } \\
\text { (E. coli } 31-\mathrm{B})\end{array}$ & $7.918(0.639)$ & $3.823(0.891)^{\dagger+}$ & $3.673(0.932)^{\dagger}$ & Sterile & Sterile \\
\hline $\begin{array}{l}\text { Group II } \\
\text { (E. coli BH-5) }\end{array}$ & $6.235(0.235)^{* *}$ & $2.835(0.812)^{*+\dagger \dagger}$ & $6.013(0.529)^{* * \cdot++}$ & Sterile & Sterile \\
\hline
\end{tabular}

Values are expressed as mean (SD) $\log _{10} \mathrm{cfu} / \mathrm{g}$ of kidney tissue. p values are derived from Student's $t$ test. Group I versus Group II * $\mathrm{p}>0 \cdot 05$, ${ }^{* *} \mathrm{p}<0.01$; value compared to that of immediate previous time interval $+\mathrm{p}>0.05 .+\dagger \mathrm{p}<0.001$. 


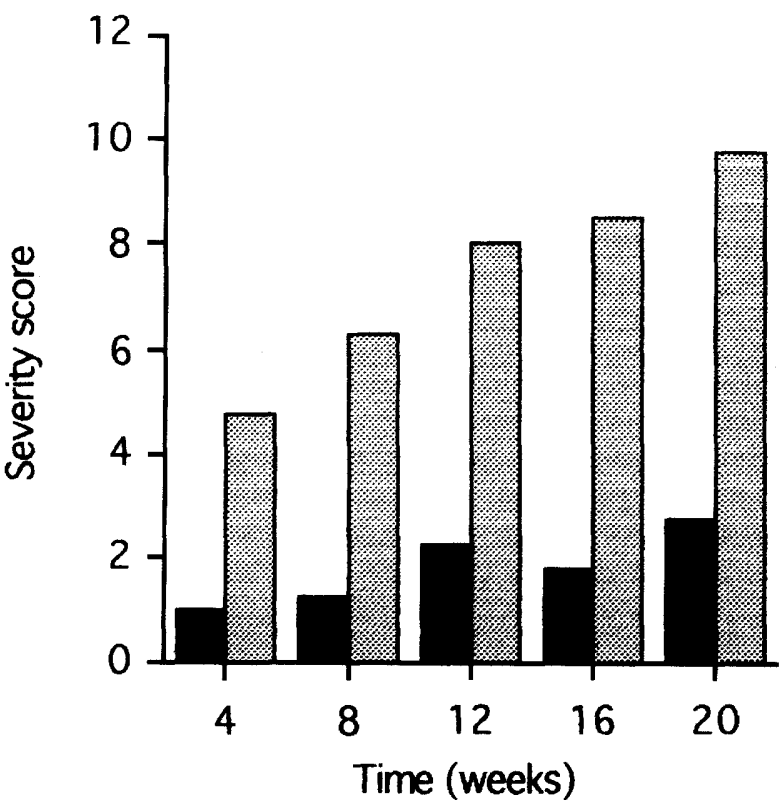

Fig. 2. Severity of histopathological lesions in infections with $E$. coli 31-B () or E. coli $\mathrm{BH}-5$ (图).

numbers, whereas the pilate strain did not. At 16 weeks after infection, the kidneys were all found to be sterile, irrespective of the strain involved.

Histopathological studies (fig. 2) showed that, despite the fact that the non-pilate strain was less effective at colonisation, it was still able to cause more renal parenchymal damage and ultimately induced scarring 5 months after infection (fig. 3 ).
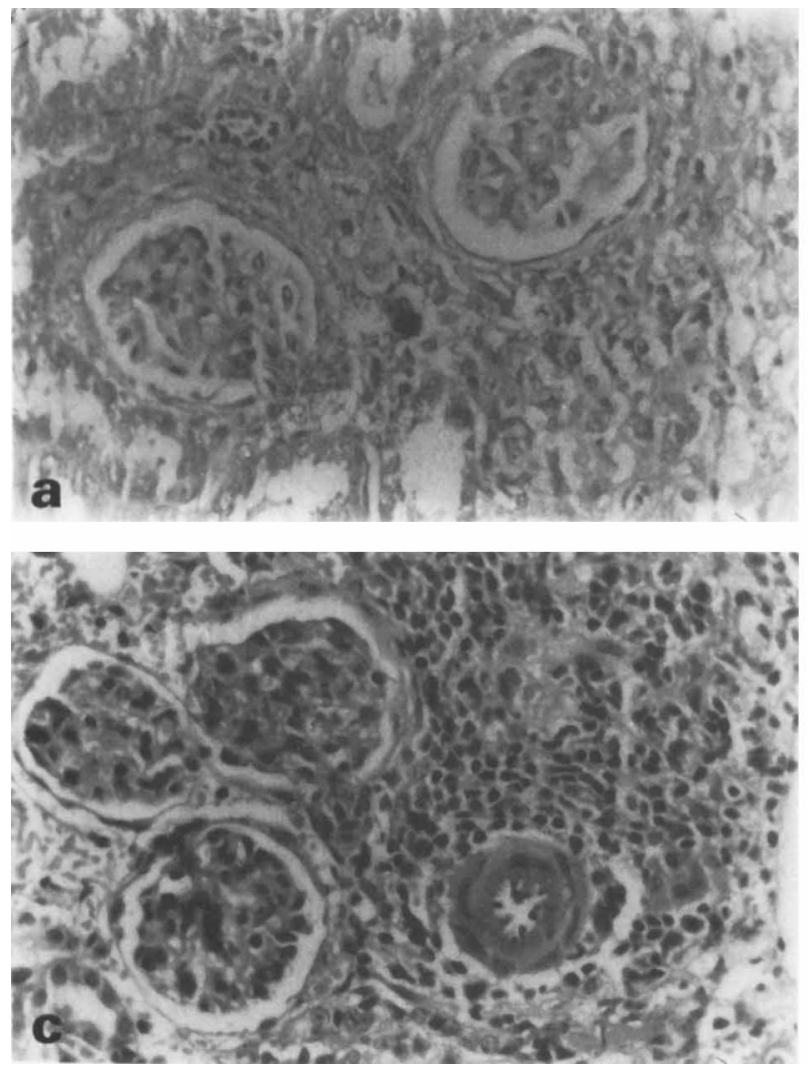

\section{Discussion}

A pre-requisite for a valid animal model of human pyelonephritis is that the uro-epithelial surface should exhibit, qualitatively and quantitatively, the same adhesive receptors for the invading organism as does that of man. In both man and BALB/c mice, receptors for type-1 pili have been detected on the epithelial surface of vagina, bladder, ureter, renal pelvis, proximal tubules and collecting ducts, but they have not been detected in the glomeruli. ${ }^{11}$ The carbohydrates of type-1 pili have been detected in the urine of man and BALB $/ \mathrm{c}$ mice. ${ }^{17}$ The urine of both species also contains a titratable factor that inhibits binding of type-1 pili to their receptors. This factor was determined to be physically, chemically and immunologically identical to the Tamm-Horsfall (T-H) glycoprotein $^{11}$ and is produced by the ascending limb of the loop of Henle and distal convoluted tubules. It is secreted into the tubular urine and represents urinary slime. This material may entrap type-1 pilate $E$. coli strains and nullify their capacity to bind to cell-surface receptors. This study revealed that the pilate $E$. coli strain (31-B) was able to colonise BALB/c mouse renal tissue much better than its non-pilate mutant at 4 weeks after infection $(p<0 \cdot 01)$. Iwahi and Imada ${ }^{12}$ also observed that the non-pilate strain (BH-5) did not readily colonise the urinary tract of mice. This may be an example of the principle that colonisation of a mucosal surface is a function of the relative molar
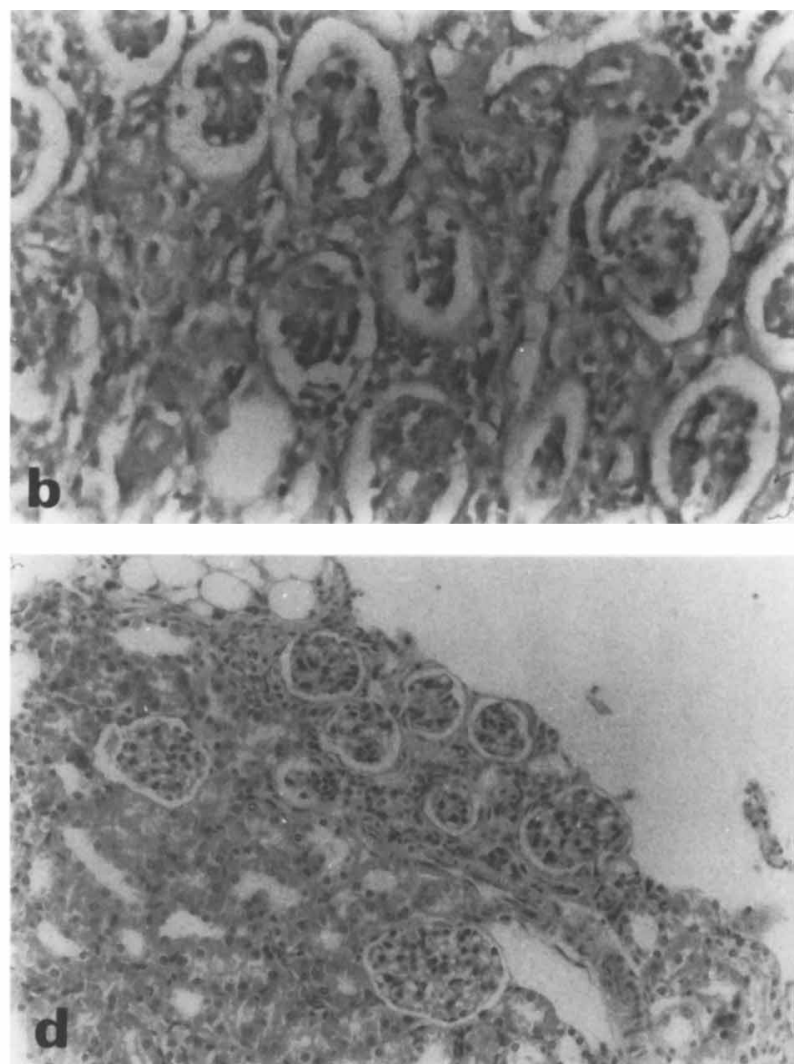

Fig. 3. Pyelonephritic changes after infection with $E$. coli $\mathrm{BH}-5$, a, photomicrograph showing extensive cortical destruction and periglomerular scarring $(\mathrm{H} \& \mathrm{E} \times 50)$; b, photomicrograph showing crowding of glomeruli and periglomerular fibrosis $(\mathrm{H} \& \mathrm{E} \times 80)$; $\mathbf{c}$, photomicrograph showing periglomerular fibrosis $(\mathrm{H} \& \mathrm{E} \times 100)$; d photomicrograph showing extensive cortical destruction and crowding of glomeruli ( $\mathrm{H} \&$ $\mathrm{E} \times 50)$. 
concentration in situ of cell-bound and free receptors and components like $\mathrm{T}-\mathrm{H}$ proteins which are produced in the kidney and excreted in urine. Furthermore. the non-pilate mutant is more prone to the flushing action of the urine in the absence of receptors in the kidney.

Eight weeks after infection a significant decrease in colonisation by $E$. coli strains $31-\mathrm{B}$ and $\mathrm{BH}-5$ was observed $(\mathrm{p}<0.01)$ but the pilate strain $31-\mathrm{B}$ still showed higher bacterial counts than the non-pilate mutant, BH-5. However, the difference was not statistically significant $(\mathrm{p}>0.01)$.

However, after 12 weeks, an increase in the bacterial counts of strain BH-5 was observed but there was no change in those of strain 31-B. We propose that in the early stages. the possession of type-1 pili has helped colonisation but this is not related to the ultimate ability of the organism to establish itself and survive. The fate of the organism in the later stages is determined by other factors which may be environmental or reflect the interaction of virulence factors of the organism with the host factors in vivo. Furthermore, both strains have already been shown to exhibit antiphagocytic activity towards PMNLs. ${ }^{12}$ Strain $\mathrm{BH}-5$ expressed resistance to phagocytosis which was not due to a decrease in its ability to adhere to PMNLs but to its increased ability to resist ingestion and killing. However, after 16 weeks all the kidneys were found to be sterile irrespective of which strain was involved. Guze et al. ${ }^{1 *}$ showed that this could be the effect of a very high level of opsonising antibodies at this point

\section{References}

1. Lipsky BA. Urinary tract infections in men. Epidemiology, pathophysiology, diagnosis, and treatment. Ann Intern Med 1989; 110: 138-150.

2. Kunin CM. Genitourinary infections in the patient at risk: extrinsic risk factors. $\mathrm{Am} \mathrm{J} \mathrm{Med} \mathrm{1984;} \mathrm{76:} \mathrm{131-139.}$

3. Stamey TA. Sexton CC. The role of vaginal colonization with enterobacteriaceae in recurrent urinary infections. $J$ Urol $1975 ; 113: 214-217$.

4. Fowler JE, Stamey TA. Studies of interoital colonization in women with recurrent urinary infections. $X$. Adhesive properties of Escherichia coli and Proteus mirabilis: lack of correlation with urinary pathogenicity. J Urol 1977; 120: 315-318.

5. Kaijser B. Larsson P. Experimental acute pyelonephritis caused by enterobacteria in animals. A review. J Urol 1982; 127: 786-790.

6. Hagberg L, Engberg I, Freter R, Lam J, Olling S, SvanbergEdén, $C$. Ascending unobstructed urinary tract infection in mice caused by pyelonephritogenic Escherichia coli of human origin. Infect Immun 1983; 40: 273-283.

7. Korhonen TK. Leffler H, Svanborg-Edén C. Binding specificity of piliated strains of Escherichia coli and Salmonella typhimurium to epithelial cells, Saccharomyces cerevisiae cells and erythrocytes. Infect Immun 1981; 32: 796-804.

8. Naiki M. Marcus DM. An immunochemical study of the human blood groups P1, P, and PK glycosphingolipid antigens. Biochemistry $1975 ; 14: 4837-4841$.

9. Topley N. Steadman R. Mackenzie RK, Knowleden JM, Williams JD. Type I fimbriate strains of Escherichia coli initiate renal parenchymal scarring. Kidney Int 1989; 36: 609-616.

10. Lyrela TA. Gross SK. McCluer RH. Glycosphingolipid in the course of the infection which can help in clearing the organisms. They further reported that phagocytosed bacteria can survive within lysosomal vacuoles as long as they are non-opsonised, possibly because of the low levels of the myeloperoxidase activity in lysosomes containing non-opsonised bacteria.

A study of the pathological changes reveals that in spite of the fact that the non-pilate strain was less effective at colonisation, it was still able to cause more renal parenchymal damage at all stages of infection and ultimately was able to induce scarring after 5 months in $60 \%$ of the animals. The contribution of excessive release of reactive oxygen metabolites (ROS) from PMNLs bringing about adventitious damage of surrounding tissue needs to be studied. The suggestion has been made that if the bacteria remain extracellularly attached and continue triggering the release of ROS and lysosomal enzymes without being ingested, this may potentiate the inflammatory process. $^{19}$

Thus, chronic pyelonephritis can be induced in $\mathrm{BALB} / \mathrm{c}$ mice by employing an ascending route of infection and this model can be used to study the pathogenesis of the disease process.

We thank Dr T. Iwahi. Takeda Chemical Industries Ltd, Japan for supplying the standard strains. We are also grateful to the Central Scientific Institute of Research, New Delhi for financial help to complete this project. patterns in primary mouse kidney cultures. J Cell Physiol 1986; 129 : 390-394.

11. O'Hanley P. Vaccines against Escherichia coli urinary tract infections. New Generation Vaccines $1990 ; 30: 270-284$.

12. Iwahi T, Imada A. Interaction of Escherichia coli with polymorphonuclear leukocytes in pathogenesis of urinary tract infection in mice. Infect Immun 1988; 56: 947-953.

13. Sinha N, Harjai K, Sharma S. Ascending pyelonephritis model in Swiss Webster (LACA) mice. Ind J Med Res 1988; 88: $541-544$.

14. Tuan $\mathrm{H}$, Briedigkeit $\mathrm{H}$, Ditschertein $\mathrm{G}$ et al. The route of infection and spreading of Escherichia coli in the kidneys in the experimental pyelonephritis in rats. Acta Biol Med Germ 1970; 25: 679-691 (in German).

15. Schaeffer AJ, Schwan WR, Hultgren SJ, Duncan JL. Relationship of type I pilus expression in Escherichia coli to ascending urinary tract infections in mice. Infect Immun 1987; 55: 373-380.

16. Garg UC, Ganguly NK, Sharma S, Chakravarti RN, Bhatnagar RK. Quantitative histopathological methods for the evaluation of experimental ascending pyelonephritis. Med Sci Res 1987; 15: 367-368.

17. O'Hanley P, Low D, Romero I et al. Gal-Gal binding and hemolysin phenotypes and genotypes associated with uropathogenic Escherichia coli. $N$ Engl J Med 1985; 313: 414420 .

18. Guze LB, Montgomerie JZ, Potter CS, Kalmanson GM. Pyelonephritis XVI. Correlates of parasite virulence in acute ascending Escherichia coli pyelonephritis in mice undergoing diuresis. Yale J Biol Med 1973; 46: 203-211.

19. Mundi H, Björkstén B, Svanborg C, Öhman L, Dahlgren C. Extracellular release of reactive oxygen species from human neutrophils upon interaction with Escherichia coli strains causing renal scarring. Infect Immun 1991; 59: 4168-4172. 